University of Nebraska - Lincoln

DigitalCommons@University of Nebraska - Lincoln

1996

Cuticular Hydrocarbons of Glacially-Preserved Melanoplus (Orthoptera: Acrididae): Identification and Comparison with Hydrocarbons of M. sanguinipes and M. spretus

\author{
Bruce D. Sutton \\ Florida Department of Agriculture \\ David A. Carlson \\ University of Florida \\ Jeffrey A. Lockwood \\ University of Wyoming \\ Richard A. Nunamaker \\ USDA-ARS
}

Follow this and additional works at: https://digitalcommons.unl.edu/entomologyother

Part of the Entomology Commons

Sutton, Bruce D.; Carlson, David A.; Lockwood, Jeffrey A.; and Nunamaker, Richard A., "Cuticular Hydrocarbons of Glacially-Preserved Melanoplus (Orthoptera: Acrididae): Identification and Comparison with Hydrocarbons of M. sanguinipes and M. spretus" (1996). Entomology Papers from Other Sources. 10.

https://digitalcommons.unl.edu/entomologyother/10

This Article is brought to you for free and open access by the Entomology Collections, Miscellaneous at DigitalCommons@University of Nebraska - Lincoln. It has been accepted for inclusion in Entomology Papers from Other Sources by an authorized administrator of DigitalCommons@University of Nebraska - Lincoln. 


\title{
Cuticular Hydrocarbons of Glacially-Preserved Melanoplus (Orthoptera: Acrididae): Identification and Comparison with Hydrocarbons of $M$. sanguinipes and $M$. spretus.
}

\author{
Bruce D. Sutton, David A. Carlson ${ }^{1}$, Jeffrey A. Lockwood ${ }^{2}$ and Richard A. Nunamaker ${ }^{3}$
}

Division of Plant Industry, Florida Department of Agriculture, Gainesville, Florida 32608

\begin{abstract}
The cuticular hydrocarbons of four groups of grasshoppers were identified and quantified by capillary column gas-liquid chromatography (GLC) and GLC-mass spectrometry (GLC-MS), including samples of: 1) a modern species, $M$. sanguinipes (Fabricius), 2) a morphologically similar extinct species, $M$. spretus Walsh, 3) 650year old fragments recovered from a receding glacier in southwestern Montana, and 4) 140-year old whole bodies from a glacier in northwestern Wyoming. Quantitative data from 20 n-alkanes and methyl- and dimethyl-branched alkanes were compared using discriminant analysis, which showed differences in cuticular hydrocarbon patterns between the putative species $M$. sanguinipes and $M$. spretus. The resulting discriminant model classified the glacially preserved whole bodies as $M$. spretus, but the identity of the fragments remains ambiguous [KEY WORDS: Grasshopper, discriminant analysis, gas-liquid chromatography, mass spectrometry, methylalkanes].
\end{abstract}

Grasshoppers of the genus Melanoplus are widespread in North America and include species which exhibit periodic swarming and mass migration. One species, M. spretus Walsh, was a major agricultural pest in the western United States and Canada through the late 1800 s until a natural population crash concentrated the species into habitats impacted by newlyintroduced and intensive agricultural practices. The coincident population decline and anthropogenic habitat destruction apparently led to its extinction in the early 1900s (Lockwood \& DeBrey 1990).

The nomenclatural histories of M. spretus and the extant and closely related, if not conspecific, $M$. sanguinipes (F.) have followed rather convoluted paths and their taxonomic status remains in dispute (Capinera \& and Sechrist 1982, Lockwood 1989, Cohn 1994, Lockwood 1996, et ante). Thomas (1865) credited Acridium spretis to an earlier unpublished manuscript by Uhler, but in 1873 he placed $A$. spretum Thomas in synonymy with Caloptenus spretus Uhler (Thomas 1873). Later workers on the melanopline grasshoppers credited C. spretus to Walsh (1866), apparently also based upon the nomenclature of Uhler. Caloptenus atlantis (Riley) was originally considered distinct from $M$. spretus (Riley 1875), but it was soon reinterpreted as a dwarf form of $M$. spretus (Packard 1877). Later authors have failed to reach consensus on the taxonomic status of these two forms. Melanoplus spretus was determined to represent the gregarious phase of M. sanguinipes by Faure (1933), Brett (1947)

\footnotetext{
${ }^{1}$ Department of Entomology and Nematology, University of Florida, Gainesville, FL 32609

${ }^{2}$ Department of Plant, Soil and Insect Sciences, University of Wyoming, Laramie, WY 82071

${ }^{3}$ USDA-ARS, Arthropod-Borne Animal Diseases Research Laboratory, Laramie, WY 82071
}

and Gurney (1953); however, Gurney and Brooks (1959) returned M. spretus to full species status. A recent morphometric analysis (Lockwood 1989) was in agreement with this. The nomenclature was further complicated with the confusion of M. mexicanus Saussure with M. sanguinipes by Hebard (1917) and others, followed by the synonymy of $M$. mexicanus with $M$. bilituratus (Walker). The nomenclatural uncertainty appears to have been more or less resolved with the discovery by Gurney of a Fabrician type of $M$. sanguinipes (F.) in Copenhagen and the synonymy of the earlier names with that species. Gurney (1962) provides a synopsis of the nomenclatural history of $M$. sanguinipes.

Recently, fragments of specimens identified as belonging to the genus Melanoplus were collected from a rapidly receding glacier, Grasshopper Glacier, Park County, Montana (Lockwood et al. 1990). These remains were radiocarbon-dated to between 650 and 850 yr before present (BP). Grasshopper Glacier, located in the Beartooth Range of Montana, has been known for at least a century for having particularly large quantities of grasshopper remains. Gurney (1953) reported that large numbers of $M$. mexicanus mexicanus (=M. spretus) had been identified from Grasshopper Glacier from as early as 1914, in addition to smaller numbers of other Melanoplus species. Lockwood et al. $(1990,1991$ a , 1992) provided a recent description of the glacial deposits of grasshoppers from three sites in Montana together with morphological comparisons of recovered Melanoplus fragments with potential conspecifics, $M$. sanguinipes and $M$. spretus. Other known sites of significant glacial entrapment of grasshoppers include the Wind River Glaciers, Fremont Co., Wyoming (Lockwood et al. 1991b, 1994). As part of an ongoing study of the glacially preserved insects of the Rocky Mountain area, intact Melanoplus were recovered from Knife Point Glacier and identified as $M$. spretus based upon morphological criteria (Lockwood et al. 1991b, 1994). These remains were radiocarbon dated to $140 \mathrm{yr}$ BP. A description of the preserved insect fauna of several of the Wind River Glaciers and a discussion of $M$. spretus was provided by Lockwood et al. (1991b, 1994).

It appeared worthwhile to attempt the recovery and analysis of cuticular hydrocarbons from these bodies and fragments for comparison with those of other Melanoplus taxa in light of two essential issues. First, we hoped that it would be possible to resolve the question of the identity of the glacially-preserved grasshoppers and to demonstrate the viability of a novel and potentially valuable diagnostic method for similar material. The male genitalia, which are hypothesized as being diagnostic features of Melanoplus species (Gurney and Brooks 1959, Cohn 1994), are rarely preserved in glacial remains, presumably due the small size of these structures and the preponderance of 
females in the deposits (Lockwood et al. 1994). In this context, investigations of unorthodox approaches to taxonomic identification are essential (Lockwood 1989, Lockwood et al. 1992, 1994), and these methods may prove valuable in studies of other poorly preserved samples (e.g., fragments recovered from the crops of birds, ant nests, archaeological sites, etc.). Second, it was our intention to shed some additional light on the taxonomic relationship between $M$. spretus and $M$. sanguinipes. Although Cohn (1994) considered the work of Gurney and Brooks (1959) to have put an end to the controversy regarding the taxonomic standing of $M$. spretus, the long and complex history of this species' taxonomic status and contemporary works synonymizing this species with $M$. sanguinipes (Capinera and Sechrist 1982) suggests that acridologists remain unconvinced that a valid species, comprised of billions of individuals, disappeared over a period of just $25 \mathrm{yr}$ (Lockwood and DeBrey 1990).

Previous analyses of the cuticular lipids of Melanoplus have included the extant species: $M$. packardi Scudder and $M$. sanguinipes (Soliday et al.1974; Nelson et al. 1984); M. differentialis (Thomas) (Nelson et al. 1984); and M. bivittatus (Say), M. femurrubrum (De Geer), and $M$. dawsoni (Scudder) (Jackson 1981). In all species, the reported hydrocarbons consisted of long-chain saturated aliphatics and have included n-alkanes in addition to internally-branched monomethylalkanes and dimethylalkanes. The primary dimethylalkanes in all species were identified as 9,19-, 11,21- and 13,23- isomers.

Thus, our purpose in this research was to determine the hydrocarbon compositions of grasshopper bodies and fragments recovered from the Grasshopper (Park Co.) and Wind River Glaciers and of museum specimens of the extinct $M$. spretus. We also undertook a reanalysis of the hydrocarbon composition of $M$. sanguinipes. These profiles were compared using discriminant analysis to determine likely associations between hydrocarbon patterns.

\section{Materials and Methods}

\section{Specimens}

The specimens examined included glacial fragments from Grasshopper Glacier, Park Co., Montana, collected August 1987 as well as whole bodies collected from the Knife Point Glacier, Fremont Co., Wyoming. Whole bodies of and/or legs of adult $M$. sanguinipes were obtained from Platte, Niobrara, Sheridan and Laramie Cos., WY and Lima, CO. Melanoplus spretus originated from Lancaster Co., NE and the Turtle Mts., ND and were collected 1890-1901.

All glacial remains and specimens of $M$. sanguinipes are deposited at the University of Wyoming, Department of Plant, Soil and Insect Sciences, Laramie, WY. The specimens of $M$. spretus are deposited at the University of Nebraska, Department of Entomology, Lincoln, NE.

All glacial remains consisted of more-or-less whole bodies (Knife Point Glacier) or disarticulated exoskeleton fragments recovered from a matrix of body parts, comprised primarily of mandibles and whole or broken femurs and tibia (Grasshopper Glacier). For gas-liquid chromatography (GLC) analysis, body parts were utilized as individual samples if sufficiently large, such as a single femur or tibia, or as a pool of several smaller fragments. Analysis by GLC-mass spectrometry (GLC-MS) utilized pooled samples of 50 to 100 fragments. Comparative samples of $M$. sanguinipes $(n=65)$ and $M$. spretus $(n=15)$ consisted of complete pinned adults in addition to pooled samples of one to three disjointed hind legs.

\section{Analytical Methods}

Each specimen was extracted by immersion in hexane and the hydrocarbons isolated from other cuticular components using silica gel mini-columns as described by Carlson et al. (1984). Analysis of cuticular components involved separation and quantitation of eluents by GLC utilizing a $0.20 \mathrm{~mm}$ i.d. $\times 30$ $\mathrm{m}$ fused-silica capillary column having a $0.20 \mu \mathrm{m} 5 \%$ diphenyl dimethyl siloxane stationary phase (SPB-5, Supelco Inc., Bellefonte, PA) fitted to a Tracor 540 gas chromatograph (Austin, TX) with a cool on-column injector (OCI-3, Scientific Glass Engineering, Austin, TX) and Tracor flame-ionization detector. $\mathrm{H}_{2}$ carrier was used with a linear flow velocity of $60 \mathrm{~cm} / \mathrm{s}$. Each sample was re-constituted in hexane as necessary to maintain a consistent stationary phase loading, and 1 to $2 \mu \mathrm{l}$ was injected. Each chromatographic run was temperature-programmed as follows: initial hold at $60^{\circ} \mathrm{C}$ for $2 \mathrm{~min}$, ramp $20^{\circ} \mathrm{C} / \mathrm{min}$ from $60^{\circ} \mathrm{C}$ to $230^{\circ} \mathrm{C}$ then $2^{\circ} \mathrm{C} / \mathrm{min}$ to $365^{\circ} \mathrm{C}$, with a final hold at $365^{\circ} \mathrm{C}$ as necessary to ensure elution of all components. Data acquisition and peak integration utilized a PE Nelson 900 Interface and Model 2100, Rev. 5.0 software (Perkin Elmer Nelson Systems, Inc., Cupertino, CA). A small number of samples was reanalyzed using a $0.22 \mathrm{~mm}$ i.d. $\times 25 \mathrm{~m}$ aluminum-clad fusedsilica capillary column having a $0.10 \mu \mathrm{m}$ carborane-dimethyl siloxane stationary phase (HT-5, Scientific Glass Engineering, Austin, TX) temperature-programmed to $400^{\circ} \mathrm{C}$ in order to determine if higher boiling point compounds were present. $\mathrm{N}$ alkane standards used to establish Kovats' Indices (KI) (Kovats 1965) included $C_{12}-C_{60}$ (PS-12-60D, SUPELCO Inc., Bellefonte, PA) and Polywax 655 (SUPELCO Inc., Bellefonte, PA). The latter provided even carbon-number n-alkanes to beyond $C_{80}$. Standards and sample, in toluene preheated to approximately $30^{\circ} \mathrm{C}$ to reduce precipitation of the higher boiling point alkanes, were co-injected at an initial temperature of $100^{\circ} \mathrm{C}$. The run parameters were otherwise as above. Kovats' Indices for the methylalkane peaks were determined by cubic spline interpolation from the n-alkane retention times with fully cubic extrapolation at the end points. Electron-impact (EI) mass spectra were obtained using a Hewlett-Packard 5988A Mass Spectrometer (MS) (Hewlett-Packard Co., Atlanta, GA) interfaced to a HP 5890 gas chromatograph fitted with an OCI-3 injector. The column and chromatographic parameters were as above, except for the use of $\mathrm{He}$ carrier at a linear velocity of $40 \mathrm{~cm} / \mathrm{s}$. The MS interface was maintained at $315^{\circ} \mathrm{C}$, electron voltage at $70 \mathrm{eV}$, and the system parameters manually optimized in order to enhance the EI spectra in the critical region of $\mathrm{m} / \mathrm{z} 200$ to 500 . The mass spectral scan range extended from $\mathrm{m} / \mathrm{z} 70$ to 750 with a scan rate of approximately one scan per sec. MS scans were manually background subtracted prior to interpretation.

The identification of cuticular methylalkane components based upon EI mass spectra followed the conventions for the interpretation of such compounds established previously (Nelson \& Sukkestad 1970; Nelson et al. 1980; Carlson et al. 1984; Nelson \& Carlson 1986; Nelson et al. 1988). The use of Kovats' Indices provided a means to narrow the range of possible methyl-branch configurations in cases of ambiguous or insufficient EI spectra.

Discriminant analysis utilized linear, quadratic and kernel 
density estimate (KDE) models (Silverman 1986) with bruteforce optimization of model parameters using the jack-knifed classification error as the decision criterion. The peaks selected for analysis included the predominant isomers of the three dominating homologous series: n-alkanes, monomethylalkanes and dimethylalkanes. Each individual peak area was expressed as a percentage of the total peak area for that sample and a dissimilarity matrix of normalized Euclidean distances was constructed from the resulting matrix. Peak subsets were also evaluated as part of the discriminant model optimization. The SAS System, version 6.01, (SAS Institute Inc., Cary, NC) was utilized to construct the discriminant models and for the univariate statistics. Multivariate analysis and plotting for visualization utilized Systat, version 5.03,(SYSTAT Inc., Evanston, IL). Monotonic multidimensional scaling (MDS) using Kruskal's stress formula 1 (Kruskal 1964) was used to reduce the data dimensionality to allow two-dimensional plotting for visualization. Shepard diagrams (Shepard et al., 1972) of distances in the final configuration against input dissimilarities were used as the measure of goodness-of-fit.

\section{Results}

The hydrocarbons from the glacial fragments and the two Melanoplus species exhibited similar chromatographic patterns (Fig. 1) consisting of an overall bimodal distribution of peaks ranging from KI 2000 to KI 5350. No higher boiling point alkanes were observed beyond this region up to $\mathrm{nC}_{80}$. All hydrocarbons detected consisted of long-chain saturated aliphatic n-alkanes and methyl-branched alkanes. There was no evidence for unsaturated components in the glacial specimens, M. spretus or M. sanguinipes.

The n-alkanes and methyl-branched alkanes identified by GLC-MS are presented in Table 1. Each GLC peak is identified by a nominal KI, and the predominant isomer in co-eluting mixtures is noted when it was possible to do so with certainty. The slow MS scan rate together with overlapping diagnostic ions, particularly primary and secondary carbonium ions resulting from fragmentation of co-eluting isomers differing only in the number of methylene units between the methyl-branch points, made identification and reconstruction of relative ratios of methyl-branched isomers subject to uncertainty. In addition, the specification of a Kovat's Index for a specific chromatographic peak was complicated by relative shifts in isomer composition between individuals, particularly when the peak components, though unresolved, exhibited slight differences in retention times.

In all samples, n-alkanes were dominant and formed complete even- and odd-backbone homologous series from $\mathrm{nC}_{20}$ to $\mathrm{nC}_{35}$ or, perhaps, $\mathrm{nC}_{36}$. The odd carbon-number series was predominant with a series mode at either $\mathrm{nC}_{27}$ or $\mathrm{nC}_{29}$. Methylbranched alkanes occurred as homologous series of monomethylalkanes, dimethylalkanes, and trimethylalkanes having backbones of 25 to 53 carbons. The odd carbon-number backbone monomethylalkanes formed a complete bimodal homologous series from 25 to 49 carbons consisting of isomers having methyl-branch positions from the 3- to the 17-carbon. The predominant isomers at a specific carbon-number was either 11- or 13-branched and coeluted with the 9-, 15- and 17methylalkane isomers. The series modes were at 31 or 33 carbons and at 43 carbons. An analogous series of even-back- bone homologs was also present, albeit at a much reduced concentration. There was an overall trend with increasing chain length towards a reduction in the overall number of isomers present, but the predominant isomers remained consistent.

The dimethylalkanes also formed a complete bimodal homologous series of even- and odd-backbone isomers from 27 carbons to 53 carbons. The series modes were at 33 carbons and 49 or 51 carbons, respectively. The identified isomers ranged from $3, x-$ to $17, x-$, with either the $13, x-, 11, x-$ or, rarely, $9, x-$ isomers predominant. The number of methylene units between the methyl-branch points (I) for the 3,x-dimethylalkanes ranged from $I=3$ to $I=11$ with $I=7$ or 9 most prevalent. The $5, x$ - isomers ranged from $I=3,5,7$ or 9 with $I=5$ or 7 dominant. The $7, x-$ isomers were generally $I=3$ or $I=5$. The $9, x$ - through $17, x-$ dimethylalkanes exhibited a more complex pattern in which there was a bimodality in the distribution of methylene units between the methyl-branch points at a given carbon-number. Isomers were identifiable with $\mathrm{I}=3$ and $\mathrm{I}=9,11$ and 13 ; however, intermediate numbers of methylene units between branch points did not appear to be present at detectable levels. The constraints inherent in interpreting mass spectra of such complex dimethylalkane mixtures precluded any absolute declarations; however, if the isomers having intermediate numbers of methylene units existed they were present at much lower levels than the $I=3, I=9$ and higher isomers. Internally-branched dimethylalkanes having $\mathrm{I}=3$ were predominant below 35 carbons. With increasing chain length there was a tendency towards a reduction in the number of isomers present at a given carbon-number, particularly isomers having $I=3$, and the eventual loss of all but the isomers of the $11, x-$ and $13, x-$ dimethylalkanes having $\mathrm{I}=9$ or higher. In most individuals analyzed, the shift in dominance between the $I=3$ and $I=9$, or greater, dimethylalkane isomers occurred at 35 carbons. EI mass spectra from the front of the partially resolved peak at KI 3555 (Fig. 2) showed major fragments at m/z 196/197, 224/225, $252 / 253,267,295,323$, and 351 . Successive scans in this region showed that the larger fragments at $\mathrm{m} / \mathrm{z} 224$ /225, 252 / 253, 295 and 323 were strongly correlated. The predominance of the even-numbered ions at $\mathrm{m} / \mathrm{z} 224 / 225$ and 252/253 indicated that these resulted from fragmentation internal to the methylbranched carbons. This was consistent with a 35 carbon backbone dimethylalkane having a 15,19- methyl-branching sequence. The remaining fragments were interpreted as the 13,17homolog. EI-MS scans at the rear of this peak showed major fragments at $\mathrm{m} / \mathrm{z} 168 / 169,196 / 197,224 / 225,323,351$ and 379. Successive scans in this region indicated that the $\mathrm{m} / \mathrm{z}$ 196/197 and 351 fragments were strongly correlated. The lack of a second even/odd pair with the even-ion dominant indicated that the methyl-branching is symmetric. This was consistent with the 13,23- isomer. The remaining major fragments were also correlated in successive scans and were identified as the 11,21-homolog. EI-MS scans from the central region of the peak showed only the fragments expected from the overlap of the $I=3$ and $\mathrm{I}=9$ isomers. There was no evidence for homologs having intermediate numbers of methylene units between the methylbranch points. The even-backbone dimethylalkanes showed similar patterns of even and odd methyl-branch position homologs.

Trimethylalkanes were far less abundant than either the mono- or dimethylalkanes and consisted primarily of $9, x, y-$, $11, x, y^{-}, 13, x, y-$ and $15, x, y-$ isomers having three methylene 

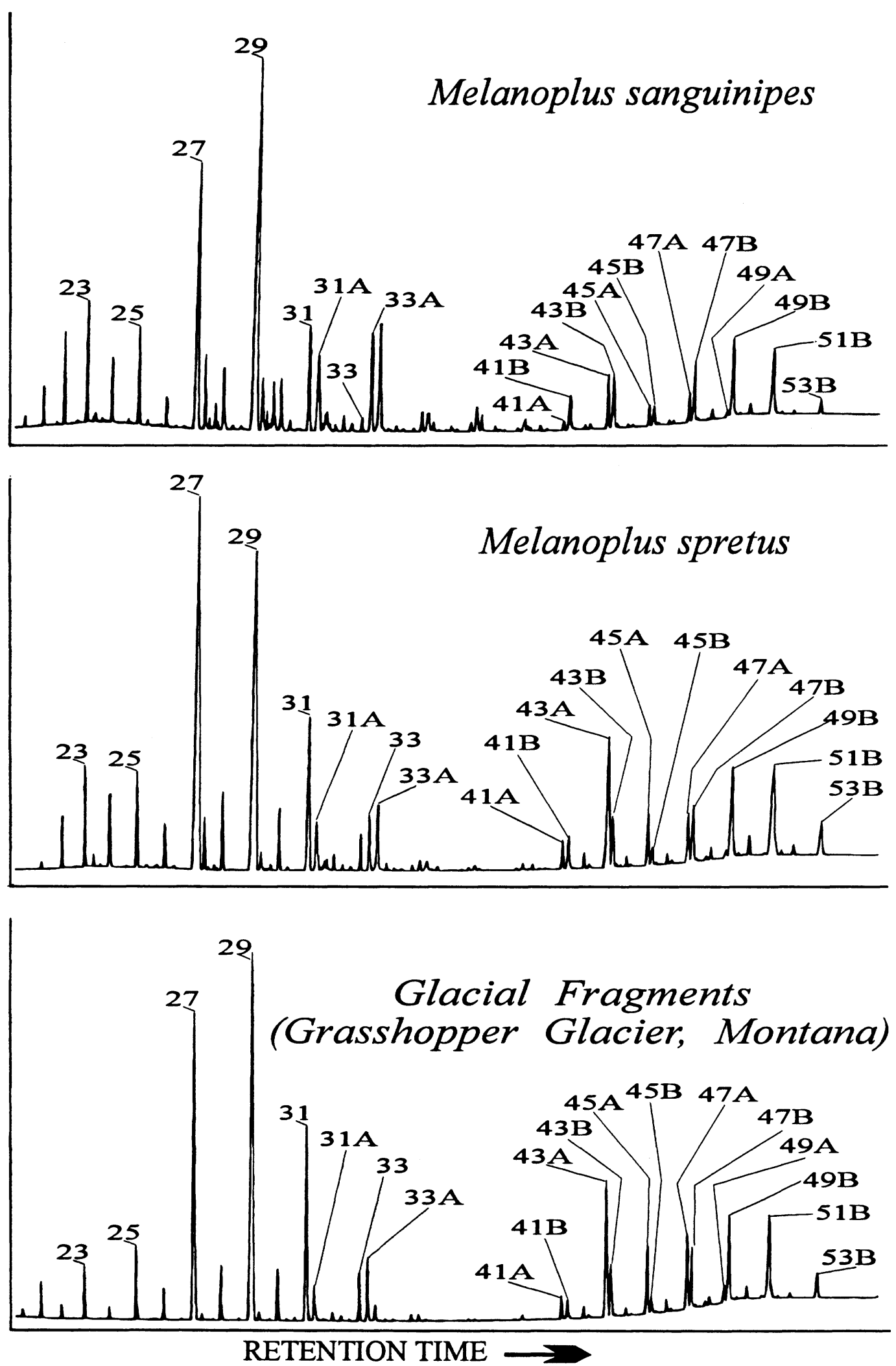

Fig. 1. Gas chromatographic profiles of cuticular hydrocarbons from Melanoplus grasshoppers: M. sanguinipes, WY, Platte Co., Wheatland, VII 261937 (adult). M. spretus: NE, Lancaster Co., Lincoln, ca 1900 (adult). Glacial remains, MT, Park Co., Grasshopper Glacier, August 1987 (pooled femurs and tibia). Peaks used in quantitative analysis labeled by peak number. 


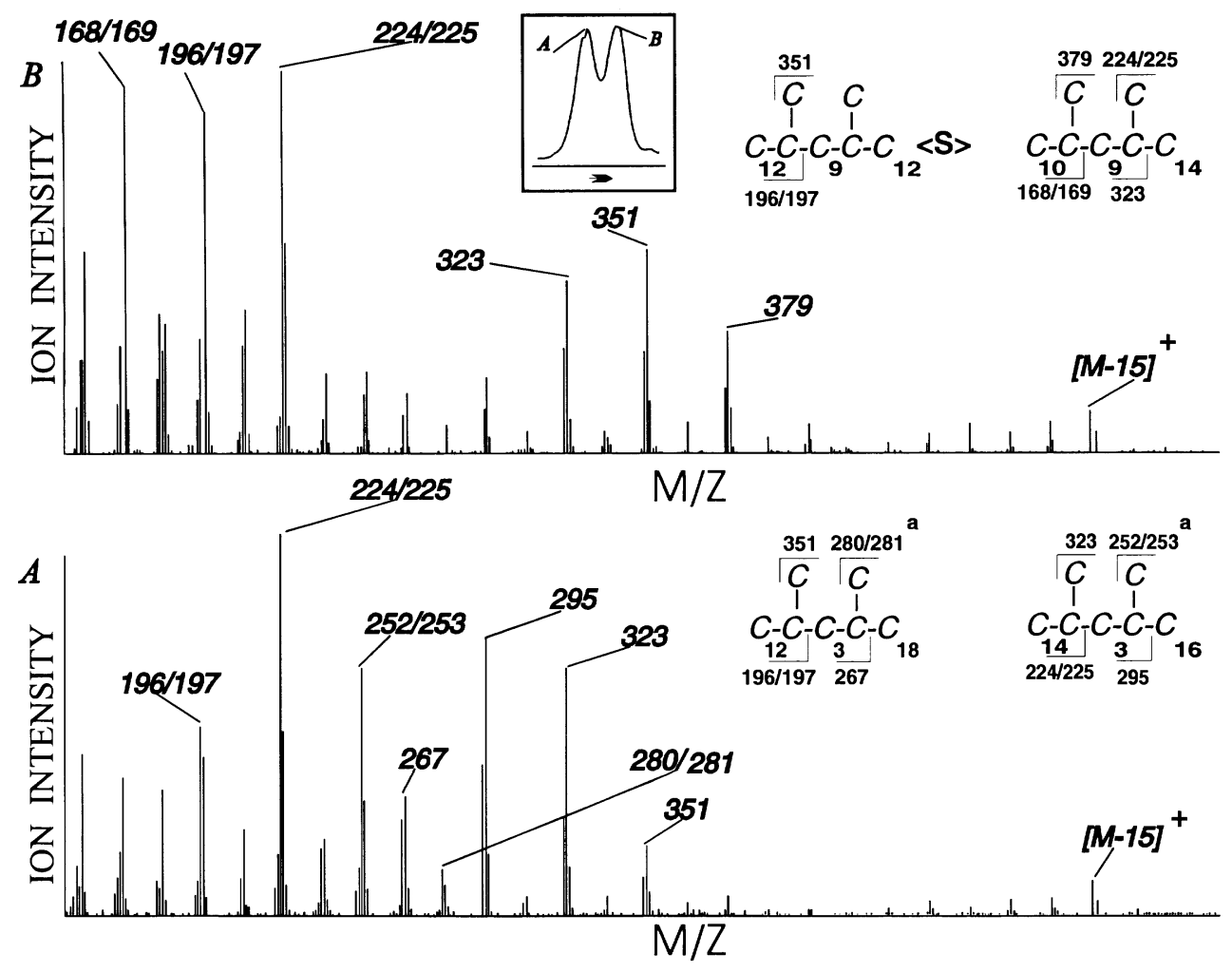

Fig. 2. Mass spectra of partially resolved $C_{35}$ dimethylalkanes having three and nine, or higher, methyl units between the methyl branch points. M. sanguinipes, WY, Platte Co., Wheatland, VII 261937 (adult); peak no. 74.

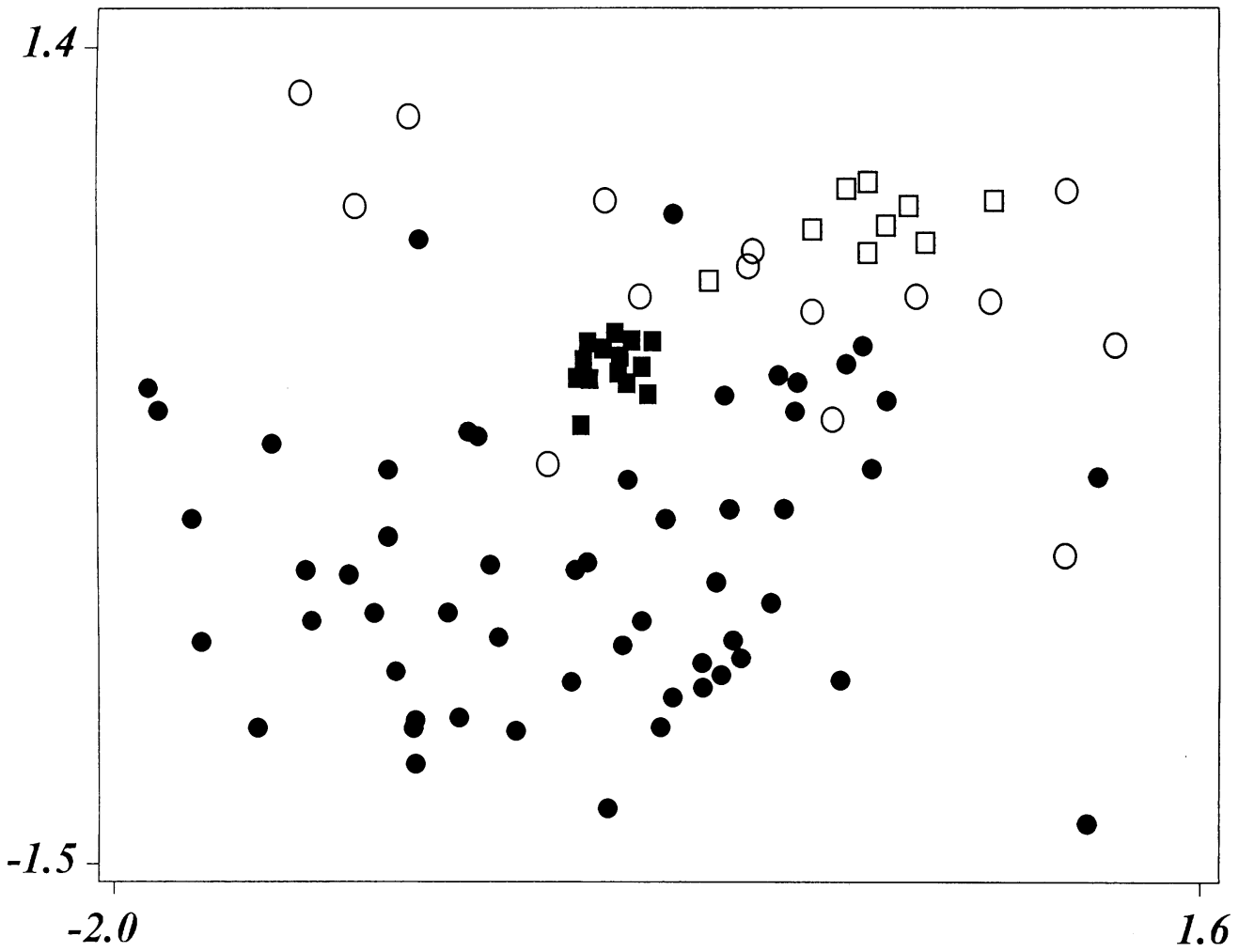

Fig. 3. Multidimensional Scaling plot of Melanoplus sanguinipes, M. spretus, and specimens from Grasshopper and Knife Point Glaciers: closed circles $=M$. sanguinipes, open circles $=M$. spretus, closed squares = Grasshopper Glacier, open squares $=$ Knife Point Glacier. 
Table 1. N-alkane and methyl-branched alkane isomers of Melanoplus sanguinipes, M. spretus and Grasshopper Glacier specimen fragments.

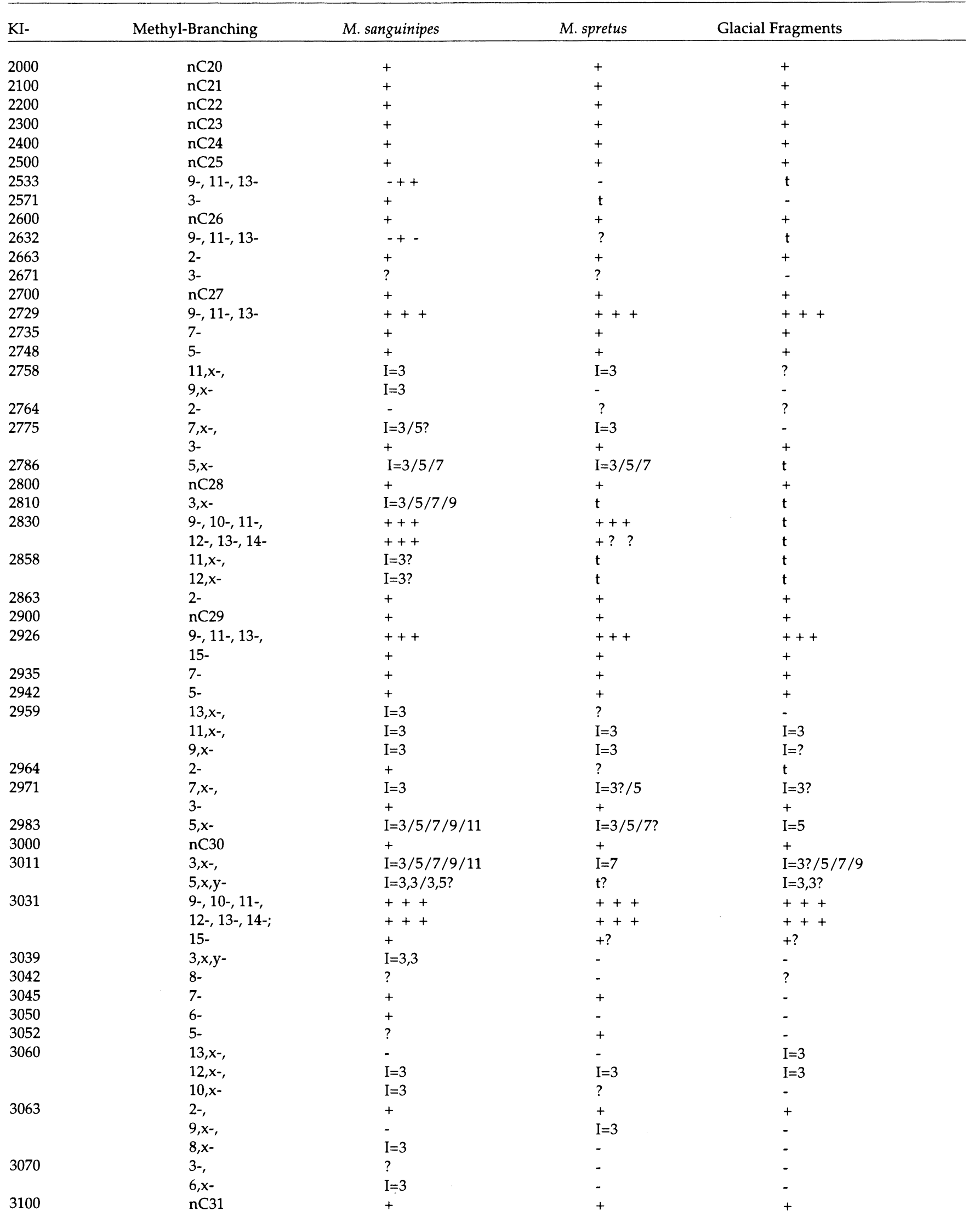


Table 1 continued

\begin{tabular}{|c|c|c|c|c|}
\hline KI- & Methyl-Branching & M. sanguinipes & M. spretus & Glacial Fragments \\
\hline 3129 & $\begin{array}{l}9-, 11-, 13-, \\
15-\end{array}$ & $\begin{array}{l}+++ \\
+\end{array}$ & ++ & $\begin{array}{l}+++ \\
?\end{array}$ \\
\hline 3141 & 7 & + & + & + \\
\hline 3152 & $5-$ & + & + & + \\
\hline \multirow[t]{3}{*}{3160} & $13, x-$ & $I=3$ & $\mathrm{I}=3 ?$ & - \\
\hline & $11, x-$ & $I=3 / 9$ & $\mathrm{I}=9$ & $\mathrm{I}=9$ \\
\hline & $9, x-$ & $\mathrm{I}=3 / 11 / 13 ?$ & $\mathrm{I}=11 ? / 13$ & $\mathrm{I}=9 ? / 11 / 13$ \\
\hline 3163 & $2-$ & ? & $?$ & $?$ \\
\hline \multirow[t]{2}{*}{3172} & $7, x-$ & $\mathrm{I}=3 / 5$ & - & - \\
\hline & $3-$ & + & + & + \\
\hline 3185 & $5, x-$ & $\mathrm{I}=3 / 5 / 7$ & $\mathrm{I}=3 / 5 / 7$ & $\mathrm{I}=5 / 7$ \\
\hline 3200 & $\mathrm{nC} 32$ & + & + & + \\
\hline \multirow[t]{2}{*}{3209} & $3, x-$ & $\mathrm{I}=5 / 7 / 9 / 11$ & $\mathrm{I}=7 / 9 ?$ & $t$ \\
\hline & $5, x, y-$ & $\mathrm{I}=3,3 ?$ & $I=3,3$ & $t$ \\
\hline \multirow[t]{2}{*}{3230} & $9-, 10-, 11-, 13-$ & ++++ & ++++ & -+++ \\
\hline & $13-, 14-, 15-, 16-$ & $++? ?$ & $++? ?$ & $+?--$ \\
\hline \multirow[t]{2}{*}{3242} & $8-$, & + & + & - \\
\hline & $3, x, y-$ & $I=3,3$ & $?$ & - \\
\hline 3250 & $6-$ & + & - & - \\
\hline \multirow[t]{4}{*}{3260} & $13, x-$ & $I=9$ & $\mathrm{I}=?$ & - \\
\hline & $12, x-$ & $?$ & $?$ & - \\
\hline & $11, x-$ & $\mathrm{I}=9$ & $\mathrm{I}=9$ & $\mathrm{I}=9$ \\
\hline & $10, x-$ & $\mathrm{I}=3 / 11$ & $\mathrm{I}=11$ & $\mathrm{I}=11 ?$ \\
\hline 3264 & $2-$ & ? & $?$ & + \\
\hline 3300 & $\mathrm{nC} 33$ & + & + & + \\
\hline \multirow[t]{2}{*}{3332} & $9-, 11-, 13-$, & +++ & +++ & +++ \\
\hline & $15-, 17-$ & ++ & ++ & $? ?$ \\
\hline 3343 & $7-$ & + & + & + \\
\hline \multirow{3}{*}{3361} & $13, x-$ & $\mathrm{I}=$ ? & $\mathrm{I}=9 ?$ & - \\
\hline & $11, x-$ & $\mathrm{I}=3 ? / 9 / 11$ & $\mathrm{I}=9 / 11$ & $\mathrm{I}=9 / 11$ \\
\hline & $9, x-$ & - & $\mathrm{I}=13 ?$ & - \\
\hline \multirow[t]{2}{*}{3371} & $7, x-$ & $\mathrm{I}=3 ? /$ (large?) & $?$ & $\mathrm{I}=3 / 5 ?$ \\
\hline & $3-$ & + & $?$ & ? \\
\hline 3383 & $5, x-$ & $\mathrm{I}=3 ? / 5 / 7$ & $\mathrm{I}=5 / 7 ?$ & $\mathrm{I}=5 / 7 ?$ \\
\hline 3400 & $\mathrm{nC} 34$ & + & + & + \\
\hline 3411 & $3, x-$ & $\mathrm{I}=5 ? / 7 / 9$ & - & - \\
\hline \multirow[t]{2}{*}{3431} & $11-, 12-, 13-, 14-$ & ++++ & $+++?$ & $+++?$ \\
\hline & $15-, 16-, 17-$ & $+? ?$ & ? ? ? & ? ? ? \\
\hline \multirow[t]{6}{*}{3460} & $15, x-$ & $I=3$ & - & $t$ \\
\hline & $14, x-$ & $I=3$ & - & - \\
\hline & $13, x-$ & - & - & - \\
\hline & $12, x=$ & $\mathrm{I}=3 ? / 9$ & $I=9$ & - \\
\hline & $11, x-$ & $\mathrm{I}=3 ? / 9 / 11$ & $\mathrm{I}=9$ & - \\
\hline & $10, x-$ & $\mathrm{I}=3 ? / 9 / 11$ & - & - \\
\hline 3500 & nC35 & + & + & + \\
\hline \multirow[t]{2}{*}{3530} & $9-, 11-, 13-$, & +++ & $?++$ & -++ \\
\hline & $15-, 17$ & ++ & ++ & $? ?$ \\
\hline \multirow[t]{4}{*}{3556} & $15, x-$ & $I=3$ & - & - \\
\hline & $13, x-$ & $\mathrm{I}=3 / 9$ & $I=9$ & $?$ \\
\hline & $11, x-$ & $\mathrm{I}=9 / 11 / 13$ & $\mathrm{I}=9 / 11 / 13 ?$ & $\mathrm{I}=/ 9 ? / 11$ \\
\hline & $9, x-$ & $\mathrm{I}=11$ or $13 ?$ & - & - \\
\hline 3571 & $7, x-$ & $\mathrm{I}=3 / 5$ & - & - \\
\hline \multirow[t]{3}{*}{3580} & $13, x, y-$ & $\mathrm{I}=3,3$ & $\mathrm{t}$ & $?$ \\
\hline & $11, x, y-$ & $\mathrm{I}=3,3$ & - & - \\
\hline & $9, x, y-$ & $\mathrm{I}=3,3 ?$ & - & - \\
\hline 3600 & $\mathrm{nC} 36$ & $\mathrm{t}$ & - & - \\
\hline \multirow{4}{*}{$\begin{array}{l}3612 \\
3630\end{array}$} & $3, x-$ & $\mathrm{I}=9 / 11 ?$ & - & - \\
\hline & $9-, 10-, 11-, 12-$ & $?+++$ & -++ & $\mathrm{t}$ \\
\hline & $13-, 14-, 15-, 16-$ & $+++t$ & $?+? ?$ & \\
\hline & $17-, 18$ & ++ & $? ?$ & \\
\hline
\end{tabular}


Table 1 continued

\begin{tabular}{|c|c|c|c|c|}
\hline KI- & Methyl-Branching & M. sanguinipes & M. spretus & Glacial Fragments \\
\hline \multirow[t]{4}{*}{3655} & $16, x-$ & $I=3$ & - & $t$ \\
\hline & $15, x-$ & $I=3$ & - & \\
\hline & $13, x-$ & $I=3$ & - & \\
\hline & $12, x-$ & $\mathrm{I}=9 / 11$ & $?$ & \\
\hline $11, x-$ & $\mathrm{I}=9 / 11 ?$ & $\mathrm{I}=11$ & & \\
\hline 3678 & $12, x, y-$ & $\mathrm{I}=3,3$ & - & - \\
\hline 3700 & $\mathrm{nC} 37$ & $?$ & - & - \\
\hline 3728 & $\begin{array}{l}11-, 13-, 15- \\
17-, 19-\end{array}$ & $\begin{array}{l}+++ \\
++\end{array}$ & $\begin{array}{l}++? \\
-\end{array}$ & $\begin{array}{l}++- \\
--\end{array}$ \\
\hline \multirow[t]{2}{*}{3754} & $17, x-$ & $I=3$ & - & - \\
\hline & $15, x-$ & $I=3$ & - & - \\
\hline 3778 & $11, x, y-$ & $\mathrm{I}=3,3$ & & - \\
\hline 3827 & $12-, 13-, 14$ & ++ & - & - \\
\hline \multirow[t]{6}{*}{3853} & $17, x-$ & $I=3$ & $t$ & - \\
\hline & $16, x-$ & $\mathrm{I}=3$ & & - \\
\hline & $15, x-$ & $\mathrm{I}=3 ?$ & & - \\
\hline & $14, x-$ & $?$ & & - \\
\hline & $13, x-$ & $I=9$ & & - \\
\hline & $12, x-$ & $I=9$ & & - \\
\hline \multirow[t]{3}{*}{3877} & $14, x, y-$ & $\mathrm{I}=3,3$ & - & - \\
\hline & $13, x, y-$ & $\mathrm{I}=3,3$ & - & - \\
\hline & $12, x, y-$ & $\mathrm{I}=3,3$ & - & - \\
\hline \multirow[t]{2}{*}{3925} & $11-, 13-, 15-$, & ++ & ++- & +++ \\
\hline & $17-, 19-$ & ++ & - & - \\
\hline 4028 & $11-, 12-, 13-$ & ++ & - & $t$ \\
\hline \multirow[t]{2}{*}{4050} & $11, x-$ & $\mathrm{I}=9 / 11 ?$ & $t$ & $t$ \\
\hline & $9, x-$ & $\mathrm{I}=3$ & & \\
\hline 4127 & $11-, 13-$ & ++ & ++ & ++ \\
\hline \multirow[t]{3}{*}{4150} & $13, x-$ & $\mathrm{I}=7 / 9$ & $\mathrm{I}=9$ & $\mathrm{I}=?$ \\
\hline & $11, x-$ & $\mathrm{I}=9 / 11$ & $\mathrm{I}=9 / 11 ?$ & $\mathrm{I}=9 / 11$ \\
\hline & $9, x-$ & $\mathrm{I}=3$ & $\mathrm{I}=3$ & $\mathrm{I}=3$ \\
\hline 4171 & $7, x-$ & $\mathrm{I}=3 / 5$ & $?$ & - \\
\hline \multirow[t]{2}{*}{4227} & $11-, 12-, 13-$ & $?++$ & -++ & +++ \\
\hline & $14-$ & $?$ & - & - \\
\hline \multirow[t]{3}{*}{4249} & $13, x-$ & $\mathrm{I}=9$ & $\mathrm{I}=9$ & $\mathrm{I}=9 ?$ \\
\hline & $12, x-$ & $I=9$ & $I=9$ & $\mathrm{I}=9 ?$ \\
\hline & $\dot{y, x-}$ & $\mathrm{I}=3$ & - & - \\
\hline 4327 & $11-, 13-$ & ++ & $?+$ & ++ \\
\hline \multirow[t]{3}{*}{4347} & $13, x-$ & $\mathrm{I}=9$ & $\mathrm{I}=9$ & $\mathrm{I}=9$ \\
\hline & $11, x-$ & $I=9$ & $\mathrm{I}=9 ? / 11$ & $\mathrm{I}=9 / 11$ \\
\hline & $9, x-$ & $\mathrm{I}=3$ & $\mathrm{I}=3$ & $\mathrm{I}=3$ \\
\hline 4366 & $9, x, y-$ & $\mathrm{I}=3,5 ?$ & - & $\mathrm{I}=3,5 ?$ \\
\hline 4427 & $11-, 12-, 13-, 14-$ & ++++ & $-++?$ & --+ \\
\hline \multirow{2}{*}{4445} & $13, x=$ & $\mathrm{I}=9 ?$ & $\mathrm{t}$ & t \\
\hline & $12, x-$ & $\mathrm{I}=9 ?$ & & \\
\hline 4524 & $11-, 13-$ & ++ & ++ & ++ \\
\hline
\end{tabular}

Table 1 continues 
Table 1 continued

\begin{tabular}{|c|c|c|c|c|}
\hline KI- & Methyl-Branching & M. sanguinipes & M. spretus & Glacial Fragments \\
\hline \multirow[t]{3}{*}{4544} & $13, x-$ & $\mathrm{I}=9 / 11 ?$ & $\mathrm{I}=9 / 11$ & $\mathrm{I}=9 / 11 ?$ \\
\hline & $11, x-$ & $\mathrm{I}=9 / 11$ & $\mathrm{I}=9 / 11$ & $\mathrm{I}=9 / 11$ \\
\hline & $9, x-$ & $I=3$ & $\mathrm{I}=3$ & $\mathrm{I}=3$ \\
\hline 4581 & $9, x, y-$ & $\mathrm{I}=3,3 ?$ & $t$ & $\mathrm{t}$ \\
\hline 4624 & $11-, 12-, 13-$ & +++ & $? ?+$ & +++ \\
\hline 4645 & $11, x-$ & $I=9$ & $\mathrm{I}=?$ & $\mathrm{t}$ \\
\hline 4723 & $11-, 13-$ & ++ & ++ & ++ \\
\hline \multirow[t]{2}{*}{4746} & $13, x-$ & $\mathrm{I}=?$ & - & - \\
\hline & $11, x-$ & $\mathrm{I}=9 / 11 ?$ & $\mathrm{I}=9 / 11$ & $\mathrm{I}=9 / 11 ?$ \\
\hline 4824 & $11-, 12-, 13-$ & +++ & $t$ & +++ \\
\hline \multirow[t]{3}{*}{4846} & $13, x-$ & $\mathrm{I}=9$ & - & - \\
\hline & $12, x-$ & $?$ & $?$ & $?$ \\
\hline & $11, x-$ & $I=9$ & $\mathrm{I}=9 ?$ & $I=9$ \\
\hline 4923 & $11-, 13-$ & ++ & $?+$ & ++ \\
\hline \multirow[t]{2}{*}{4945} & $13, x-$ & $\mathrm{I}=9 ?$ & $\mathrm{I}=9 ?$ & $\mathrm{I}=9 ?$ \\
\hline & $11, x-$ & $\mathrm{I}=9 / 11$ & $\mathrm{I}=9 / 11 ?$ & $\mathrm{I}=9 / 11 ?$ \\
\hline \multirow[t]{3}{*}{5045} & $13, x-$ & $\mathrm{I}=9 ?$ & $\mathrm{I}=?$ & - \\
\hline & $12, x-$ & $?$ & $\mathrm{I}=?$ & $\mathrm{I}=9 ?$ \\
\hline & $11, x-$ & $\mathrm{I}=9$ & $I=?$ & $\mathrm{I}=9 ?$ \\
\hline \multirow[t]{2}{*}{5146} & $13, x-$ & $\mathrm{I}=9 / 11$ & $I=9$ & $\mathrm{I}=9$ \\
\hline & $11, x-$ & $\mathrm{I}=9 / 11$ & - & $\mathrm{I}=9 / 11$ \\
\hline 5244 & $11, x-$ & $\mathrm{t}$ & $\mathrm{t}$ & $\mathrm{t}$ \\
\hline 5340 & $13, x-$ & $t$ & $t$ & $\mathrm{t}$ \\
\hline
\end{tabular}

NOTES: $t=$ peak present at trace quantities but identification of isomers present ambiguous. $+=$ isomer present. _= predominant isomer. $=$ =isomer not present at detectable levels. ?=identification ambiguous.

units between the branch points. Less common were $3, x, y-$, $5, x, y-$ and $7, x, y$ - isomers and trimethylalkanes having greater than three methylene units between the methyl-branch points. The more internally-branched trimethylalkanes occur only at the higher carbon-numbers and always as minor components. There is no evidence for methylalkanes having more than three methyl-branches.

Twenty of the largest peaks representing the three major homologous series of n-alkanes, methylalkanes and dimethylalkanes were chosen for quantitative analysis (Table 2). Discriminant analysis results based upon these peaks are presented in Table 3. Melanoplus sanguinipes and M. spretus exhibited jack-knifed classification errors of approximately $6 \%$ and $15 \%$ respectively for the kernel density model (KDE) with an Epanechnikov kernel and a support radius of 8.0. In order to evaluate the potential for bias due to unequal sample sizes, a series of ten KDE models based upon random subsampling of the $M$. sanguinipes with $n=15$ was carried out. The classification errors for the KDE with equalized sample sizes ranged from 5 to $8 \%$ for $M$. sanguinipes and 10 to $13 \%$ for $M$. spretus. The quadratic model resulted in similar classification errors. The linear discriminant model performed poorly and was not utilized. None of the peak subsets used improved the discriminant scores. The n-alkanes by themselves resulted in the poorest separation of the taxa; however, the n-alkanes in combination with the methylalkanes exhibited the lowest classification errors.

The two-dimensional scatter plot of the data after dimension reduction by multidimensional scaling (MDS) (Fig. 3) is consistent with the results of the discriminant analysis. The fragments from Grasshopper Glacier were found to form a relatively tight cluster near the region of overlap in cuticular hydrocarbon patterns for $M$. sanguinipes and $M$. spretus. The bodies from the Knife Point Glacier clustered within the overall M. spretus cluster. The configuration seen in the MDS plot was essentially invariant with respect to subsetting of the $M$. sanguinipes, and the Shepard diagrams exhibited no evidence for degenerate solutions. Classification of the Grasshopper Glacier fragments was ambiguous. The KDE resulted in an identification of all but one of these latter samples as $M$. sanguinipes; however, this classification was found to be sensitive to the relative sample sizes for the two species used to construct the model. With random subsetting of the $M$. sanguinipes to equalize sample sizes, it was found that the number of fragments identified as M. spretus varied from one to ten. The Knife Point Glacier specimens were classified using the $\mathrm{KDE}$ as M. spretus and this remained consistent under subsetting of $M$. sanguinipes. The addition of the Knife Point Glacier material as $M$. spretus resulted in a KDE model that consistently classified the Grasshopper Glacier fragments as M. spretus. It can be seen from the MDS plot that the Grasshopper Glacier specimens have cuticular hydrocarbon patterns that are close to or within the range of overlap between $M$. sanguinipes and $M$. spretus, which is consistent with the discriminant model behavior.

The Melanoplus legs exhibited the same hydrocarbon composition as the complete body in both taxa and the MDS plots and discriminant models failed to show any consistent quantitative differences between the legs and bodies. 
Table 2. Major hydrocarbons of $M$. sanguinipes, M. spretus and glacial specimens (mean percentage of total peak area $\pm S . D$.)

\begin{tabular}{|c|c|c|c|c|c|}
\hline & & sanguinipes & M. spretus & Grasshopper Glacier & Knife Point Glacier \\
\hline Peak & \# KI & $N=65$ & $\mathrm{~N}=15$ & $\mathrm{~N}=16$ & $\mathrm{~N}=9$ \\
\hline 1 & 2300 & $2.5 \pm 1.5$ & $0.9 \pm 0.6$ & $1.6 \pm 1.5$ & $1.1 \pm 1.1$ \\
\hline 2 & 2500 & $4.2 \pm 2.7$ & $2.4 \pm 1.5$ & $3.3 \pm 2.3$ & $3.1 \pm 2.6$ \\
\hline 3 & 2700 & $16.9 \pm 6.7$ & $13.5 \pm 7.5$ & $17.0 \pm 4.9$ & $14.3 \pm 5.2$ \\
\hline 4 & 2900 & $29.2 \pm 5.4$ & $34.5 \pm 8.4$ & $25.1 \pm 6.2$ & $31.5 \pm 3.3$ \\
\hline 5 & 3100 & $8.3 \pm 2.7$ & $8.6 \pm 2.5$ & $9.5 \pm 2.7$ & $9.1 \pm 2.0$ \\
\hline 6 & 3129 & $4.6 \pm 2.8$ & $7.5 \pm 5.6$ & $2.1 \pm 0.7$ & $3.5 \pm 1.2$ \\
\hline 7 & 3300 & $1.5 \pm 0.9$ & $1.1 \pm 0.6$ & $1.6 \pm 0.4$ & $1.3 \pm 0.9$ \\
\hline 8 & 3332 & $4.8 \pm 2.8$ & $6.0 \pm 3.2$ & $2.5 \pm 0.9$ & $5.7 \pm 1.3$ \\
\hline 9 & 4127 & $1.5 \pm 0.8$ & $0.6 \pm 0.2$ & $1.3 \pm 0.6$ & $0.9 \pm 0.3$ \\
\hline 10 & 4150 & $2.0 \pm 0.9$ & $1.4 \pm 0.6$ & $1.3 \pm 0.5$ & $1.5 \pm 0.7$ \\
\hline 11 & 4327 & $4.0 \pm 1.7$ & $3.5 \pm 1.1$ & $6.7 \pm 1.1$ & $2.8 \pm 0.8$ \\
\hline 12 & 4347 & $2.5 \pm 0.8$ & $2.9 \pm 0.9$ & $3.6 \pm 1.1$ & $3.1 \pm 0.7$ \\
\hline 13 & 4524 & $1.7 \pm 0.5$ & $1.5 \pm 0.5$ & $2.8 \pm 0.6$ & $2.1 \pm 0.3$ \\
\hline 14 & 4544 & $1.1 \pm 0.7$ & $1.0 \pm 0.3$ & $1.4 \pm 0.4$ & $0.7 \pm 0.2$ \\
\hline 15 & 4723 & $2.1 \pm 0.9$ & $2.0 \pm 0.8$ & $3.2 \pm 0.9$ & $1.7 \pm 0.5$ \\
\hline 16 & 4746 & $2.4 \pm 0.6$ & $2.4 \pm 0.7$ & $3.5 \pm 0.9$ & $2.2 \pm 0.6$ \\
\hline 17 & 4923 & $0.4 \pm 0.2$ & $3.9 \pm 0.1$ & $0.8 \pm 0.3$ & $2.1 \pm 0.1$ \\
\hline 18 & 4945 & $4.0 \pm 0.9$ & $3.6 \pm 0.9$ & $5.0 \pm 1.1$ & $3.7 \pm 0.7$ \\
\hline 19 & 5146 & $4.9 \pm 1.5$ & $4.9 \pm 1.2$ & $5.9 \pm 0.9$ & $4.7 \pm 0.3$ \\
\hline 20 & 5340 & $1.4 \pm 0.5$ & $1.3 \pm 0.5$ & $1.8 \pm 0.4$ & $1.1 \pm 0.1$ \\
\hline
\end{tabular}

Table 3. Discriminant analysis of Melanoplus species and glacial fragments using a kernel density model with Epanechnikov kernel: percentage correctly classified using a jack-knifed estimator.
Into Taxa-
M. sanguinipes
M. spretus

From Taxa

$\begin{array}{lcc}\text { M. sanguinipes } & 94 & 6 \\ \text { M. spretus } & 15 & 85 \\ \text { Grasshopper Glacier } & 94 & 6 \\ \text { Knife Point Glacier } & 0 & 100\end{array}$

\section{Discussion}

Results of the GLC-MS analysis of the methyl-branched alkanes of $M$. sanguinipes are generally consistent with those previously reported for this species (Nelson et al. 1984), as well as for other Melanoplus species (Soliday et al. 1974; Jackson 1981). However, the specimens examined here suggest that the diversity of methyl-branched compounds in this species, and in Melanoplus in general, is much greater and more complex than previously indicated. The report of nine methylene units between the methyl-branch points for the internally-branched dimethylalkanes in $M$. sanguinipes represents an overly simplistic interpretation of a complex mixture of isomers. Examination of consecutive MS scans over each dimethylalkane peak and correlation of diagnostic ions indicates that each peak consisting of $9, x_{-}, 11, x_{-}, 13, x_{-}$, and higher dimethylalkane isomers involves a mixture of isomers with the earlier eluting isomers (KI $x \times 50-55)$ having $\mathrm{I}=3$ and the later eluting isomers (KI $\times \times 60-65) \mathrm{I}=9$ to $\mathrm{I}=11$ or 13 , with the dominant isomers usually $I=9$ for backbone carbon-numbers above 35 . The distribution of isomers at a given carbon-number is generally bimodal for dimethylalkanes having backbones in the range of 33 to 41 carbons and results in a partially split peak on non-polar chromatographic columns having $\geq 120,000$ theoretical plates. This peak splitting is seen in the chromatograms for the glacial specimens as well as those from $M$. sanguinipes and $M$. spretus. The relative proportions of the $I=3$ versus $I=9$ and higher isomers found in a specific peak exhibits considerable intraspecific variation and does not appear to be species specific.

Previous reports of Melanoplus cuticular methylalkane composition have not included trimethylalkanes. The overall similarity in hydrocarbon patterns between all species of Melanoplus examined to date suggests that this reflects analytical differences, particularly with respect to chromatographic resolution, between this and earlier analyses rather than taxonomic or individual variation. Internally-branched trimethylalkanes consisting of mixtures of $9, x, y^{-}, 11, x, y^{-}, 13, x, y^{-}$, and $15, x, y$ - isomers have been reported from four species of Schistocerca (Lockey \& 
Oraha 1990; Grunshaw et al. 1990) and are likely to be a common, albeit minor, component of acridid cuticular hydrocarbon patterns.

There are no clear qualitative differences in hydrocarbon composition between $M$. sanguinipes and M. spretus. Unfortunately, previous reports of cuticular lipids of other Melanoplus species (Soliday et al. 1974; Jackson 1981; Nelson et al. 1984) are difficult to compare with the present analysis because of poor resolution, and it is not yet possible to fully elucidate the range of variation in hydrocarbon composition that exists within this genus.

Quantitative differences in hydrocarbon patterns between gregarious and solitary phases of the migratory locust Locusta migratoria cinerascens have been reported (Geninet al. 1986). The proportion of long chain n-alkanes was found to be lower in solitary phase locusts than in the gregarious phase. This shift in hydrocarbon composition has not been verified for other grasshoppers having similar phase changes. The discriminant analysis results indicate that quantitative differences in hydrocarbon patterns exist between $M$. sanguinipes and M. spretus. Hebard (1917) suggested that $M$. spretus was the migratory phase of $M$. sanguinipes (Hebard 1917). However, specimens of M. sanguinipes collected from natural outbreaks differ morphometrically from M. spretus (Lockwood 1989). Early attempts to induce M. spretus from $M$. sanguinipes by altering conditions in the laboratory (e.g., crowding, food quality, temperature, and humidity) met with partial success (Faure 1933, Brett 1947). Although the evidence for conspecifity was considered generally lacking (Gurney \& Brooks 1959), some acridologists still consider M. spretus to be the gregarious or migratory phase of $M$. sanguinipes (Capinera \& Sechrist 1982).

The kernel density and quadratic discriminant models for $M$. sanguinipes and $M$. spretus exhibited similar classification errors for the n-alkanes in combination with the methylalkanes as for the methylalkanes alone. The observed differences in hydrocarbon patterns for these two putative species is not simply defined by proportional shifts in the n-alkanes. In addition, the n-alkanes by themselves resulted in poor discrimination with all of the discriminant models. Without further investigation, it is not possible to rule out a phase correlation with hydrocarbon pattern in Melanoplus that involves the methylalkanes.

The methylalkane composition of the Grasshopper Glacier fragments is similar to that of the two species of Melanoplus examined, and it is not possible to unambiguously refer the glacial fragments to either taxon based upon n-alkane and/oi methylalkane compositions only. Thus, the identification of the Grasshopper Glacier fragments remains ambiguous. The cuticular hydrocarbon patterns of these fragments are within the range of overlap between $M$. sanguinipes and $M$. spretus and cannot be identified as either with certainty.

The Knife Point Glacier specimens can be more confidently classified as $M$. spretus. The degree of sampling bias in this study is difficult to evaluate. Melanoplus spretus is poorly represented in collections both in overall numbers and geographical representation and thus may be insufficiently sampled to reflect the actual variation. Neighborhood-defined discriminant models such as the KDE can be expected to exhibit sensitivity to sampling bias; however, the KDE results were identical to that of the space-partitioning quadratic model. In addition, the classification results were robust with respect to random subsampling of the $M$. sanguinipes to equalize sample sizes.

We were quite pleased to be able to successfully recover, analyze and describe saturated hydrocarbon compounds from 600 year-old insects, although their preservation in ice was doubtlessly helpful. The remarkable similarity between the glacial fragment composition and that of the modern specimens suggests that these compounds are subject to little degradation due to weathering and that the hydrocarbon composition of Melanoplus has been relatively stable for at least half a millennium.

Although the methylalkane composition of Melanoplus has remained relatively invariant at least since the deposition of the glacial fragments, the degree of temporal stability in the cuticular hydrocarbon patterns remains unknown and the possibility that quantitative shifts have taken place cannot be ruled out. Melanoplus sanguinipes collected from a single locality over a period of years did not exhibit clear temporal shifts in pattern, but the small sample size precludes definitive conclusions.

The degree of differentiation in hydrocarbon pattern between $M$. sanguinipes and $M$. spretus is consistent with their present status as distinct taxa. Further analysis of phase-related variation in patterns within the melanopline grasshoppers will be necessary to determine to what degree this differentiation is influenced by phase shifts.

\section{Acknowledgments}

We thank G. J. Steck and the two anonymous reviewers from the FDACS, DPI, for their reading of this manuscript and critical comments. We thank J. Nation and Kathy Milne for sample preparation and preliminary GLC analysis of some samples. We also thank B. Ratcliffe, University of Nebraska, for the loan of M. spretus.

\section{Literature Cited}

Brett $\mathrm{CH}$. 1947. Interrelated effects of food, temperature, and humidity on the development of the lesser migratory grasshopper, Melanoplus mexicanus mexicanus (Saussure). Oklahoma Agric. Exp. Sta. Tech. Bull. T-26: 1-26.

Capinera JL, Sechrist TS. 1982. Grasshoppers (Acrididae) of Colorado: identification, biology and management. Colorado State Univ. Exp. Sta. Bull. 584S, 161 pp.

Carlson DA, Nelson DR, Langley PA, Coates TW, Davis TL, Leegwater-Vander Linden M. 1984. Sex pheromone in Glossina pallidipes Austen: Identification and synthesis. J. Chem. Ecol. 10: 429-450.

Cohn TJ. 1994. The use of male genitalia in taxonomy and comments on Lockwood's 1989 paper on Melanoplus spretus (Walsh). J. Orthop. Res. 3:59-63.

Faure JC. 1933. The phases of the Rocky Mountain locust Melanoplus mexicanus (Saussure). J. Econ. Entomol. 26: 706-718.

Genin E, Jullien R, Perez F, Fuzeau-Braesch S. 1986. Cuticular hydrocarbons of gregarious and solitary Locusts Locusta migratoria cinerascens. J. Chem. Ecol. 12: 1213-1238.

Grunshaw JP, Guermouche H, Guermouche S, Jago ND, Jullien R, Knowles E, Perez F. 1990. Chemical taxonomic studies in locusts of the Schistocerca americana complex (Acrididae: Cyrtacanthacridinae): chemical relationships between New World and Old World species. J. Chem. Ecol. 16: 2835-2858.

Gurney AB. 1953. Grasshopper Glacier of Montana and its relation to long-distance flights of grasshoppers. Ann. Report Smithsonian Inst. 1952, pp. 305-325.

Gurney AB. 1962. On the name of the migratory grasshopper of the United States and Canada, Melanoplus sanguinipes (F.) 
(Orthoptera, Acrididae). Proc. Biol. Soc. Washington 75: 189192.

Gurney AB, Brooks AR. 1959. Grasshoppers of the Mexicanus Group, genus Melanoplus (Orthoptera: Acrididae). Proc. U. S. Nat. Mus. 110: 1-93.

Hebard M. 1917. Notes on Mexican Melanopli (Orthoptera, Acrididae). Proc. Acad. Nat. Sci. Philadelphia 67: 251-275.

Jackson LL. 1981. Cuticular lipids of insects-IX. Surface lipids of the grasshoppers Melanoplus bivittatus, Melanoplus femurrubrum and Melanoplus dawsoni. Comp. Biochem. Physiol. 70B: 441-445.

Kovats E. 1965. Gas chromatographic characterization of organic substances in the retention index system. Adv. Chromatogr. 1: 229.

Kruskal JB. 1964. Nonmetric multidimensional scaling: a numerical method. Psycho. 29: 115-129.

Lockey KH, Oraha VS. 1990. Cuticular lipids of adult Locusta migratoria migratoriodes ( $\mathrm{R}$ and $\mathrm{F})$, Schistocerca gregaria (Forskal) (Acrididae) and other Orthopteran species-II. Hydrocarbons. Comp. Biochem. Physiol. 95B: 721-744.

Lockwood JA. 1989. Taxonomic status of the Rocky Mountain Locust: morphometric comparisons of Melanoplus spretus (Walsh) with solitary and migratory Melanoplus sanguinipes (F.). Can. Entomol. 121: 1103-1109.

Lockwood JA. 1996. Phallic Facts, Fallacies, and Fantasies: Comments on Cohn's 1994 Paper on Melanoplus spretus (Walsh). J. Orthop. Res. (in press).

Lockwood JA, DeBrey LD. 1990. A solution for the sudden and unexplained extinction of the Rocky Mountain Grasshopper, Melanoplus spretus (Walsh). Environ. Entomol. 19: 1194-1205.

Lockwood JA, Nunamaker RA, Pfadt RE, DeBrey LD. 1990. Grasshopper Glacier: Characterization of a vanishing biological resource. Amer. Entomol. 36: 18-27.

Lockwood JA, Burne JC, DeBrey LD, Nunamaker RA, Pfadt RE. 1991a. The preserved fauna of Grasshopper Glacier (Crazy Mountains, Montana): unique insights to acridid biology. 5th Proc. Orthopterists' Society. Bol. Sanidad Vegetal 20:223-236.

Lockwood JA, Thompson CD, DeBrey LD, Love CM, Nunamaker RA, Pfadt RE. 1991b. Preserved grasshopper fauna of Knife Point Glacier, Fremont County, Wyoming, U.S.A. Arct. Alp. Res. 23:108-114.

$\rightarrow$ Lockwood JA, Schell SP, Wangberg JK, Debrey WG, Bomar CR. 1992. Preserved insects and physical condition of Grasshopper Glacier, Carbon County, Montana, U.S.A. Arct. Alp. Res. 24: 229-232.
Lockwood JA, DeBrey LD, Thompson CD, Love CM, Nunamaker RA, Shaw SR, Schell SP, Bomar CR. 1994. Preserved insect fauna of glaciers of Fremont County in Wyoming: Insights into the ecology of the extinct Rocky Mountain locust. Environ. Entomol. 23: 220-235.

Nelson DR, Nunn NJ, Jackson L. 1984. Re-analysis of the methylalkanes of the grasshoppers, Melanoplus differentialis, $M$. packardii and M. sanguinipes. Insect Biochem. 6: 677-683.

Nelson DR, Sukkestad DR. 1970. Normal and branched aliphatic hydrocarbons from eggs of the tobacco hornworm. Insect Biochem. 9: 4601-4611.

Nelson DR, Fatland CL Howard RW, McDaniel CA, Blomquist GJ. 1980. Re-analysis of the cuticular methylalkanes of Solenopsis invicta and S. richteri. Insect Biochem. 10: 163-168.

Nelson DR, Carlson DA. 1986. Cuticular hydrocarbons of the tsetse flies Glossina morsitans, G.austeni and G. pallidipes. Insect Biochem. 16: 403-416.

Nelson DR, Carlson DA, Fatland CL. 1988. Cuticular hydrocarbons of the tsetse flies, II: G. p. palpalis, G. p. gambiensis, G. fuscipes, G. tachinoides and G. brevipalpis. J. Chem. Ecol. 14: 963- 987.

Packard AS. 1877. Report on the Rocky Mountain locust and other insects now injuring or likely to injure field and garden crops in the Western States and Territories. 9th Report U. S. Geol. Surv. Terr. pp. 589-809.

Riley CV. 1875. The Rocky Mountain locust-Caloptenus spretus Thomas. 7th Annual Report on Noxious and Beneficial Insects of Missouri pp. 121-196.

Shepard RN, Romney AK, Nerlove S. (Eds.) 1972. Multidimensional scaling: theory and application in the behavioral sciences. New York: Academic Press.

Silverman BW. 1986. Density estimation for statistics and data analysis. London: Chapman and Hall, 175 pp.

Soliday CL, Blomquist GJ, Jackson LL. 1974. Cuticular lipids of insects-VI. Cuticular lipids of the grasshoppers Melanoplus sanguinipes and Melanoplus packardii. J. Lipid Res. 15: 399-405.

Thomas C. 1865. Insects injurious to vegetation in Illinois. Trans. Illinois State Agric. Soc. 5: 401-468.

Thomas C. 1873. Synopsis of the Acrididae of North America. Rep. U. S. Geol. Surv. 5: 1-262.

Walsh BD. 1866. Grasshoppers and locusts. Pract. Entomol. 2: 1-5. 